\title{
Model Aplikasi Helpdesk Online Untuk Mendukung IT Support Dalam Meningkatkan Pelayanan Karyawan
}

\author{
Junaidi* ${ }^{1}$ \\ Luthfia Fauzia Dewi Aryanti ${ }^{2}$ \\ Rizky Yugho Saputra ${ }^{3}$ \\ 1,2,3Program Studi Teknik Informatika Fakultas Sains dan Teknologi Universitas Raharja \\ E-mail : * ${ }^{1}$ junaidi@ raharja.info, ${ }^{2}$ fiafauzia@ raharja.info, ${ }^{3}$ rizky.yugho@ raharja.info
}

\begin{abstract}
Abstraksi
PT. Aplus Pacific yang sudah berdiri hampir 20 tahun, semakin memperlihatkan perkembangan yang pesat. Diantaranya bertambahnya karyawan dan juga semakin kompleksnya sistem pendukung operasional manufaktur perusahaan yaitu Enterprise Resource Planning (ERP) yang digunakan oleh karyawan tersebut. Atas dasar fakta tersebutlah penelitian ini melihat potensi permasalahan yang akan timbul, yaitu menurunnya pelayanan support dari Departemen IT terhadap permintaan ataupun keluhan karyawan yang berkaitan dengan kebutuhan Teknologi Informasi baik dari sisi hardware dan juga software. Karena saat ini tim dari Departemen IT masih melayani karyawan perusahaan dengan media line telepon PABX. Hal tersebut memiliki beberapa kekurangan yang dapat menghambat proses penyelesaian masalah, seperti tidak sebandingnya line telepon yang ada dengan banyaknya keluhan di waktu yang bersamaan, sampai proses penyelesaian masalah yang relatif lama walaupun kemungkinan tim Departemen IT pernah mengalami atau menerima keluhan yang sama, dikarenakan tidak adanya basis pengetahuan yang tersimpan dengan baik. Berdasarkan hasil analisa yang dilakukan secara langsung, sistem penanganan permintaan dan keluhan yang berjalan memerlukan perubahan. Maka dari itu tujuan utama penelitian ini adalah merancang sistem Helpdesk yang dapat mengakomodir banyaknya kebutuhan dan keluhan karyawan di PT. Aplus Pacific dengan cepat dan juga tersimpan dalam log agar dapat sewaktu-waktu dilihat kembali oleh tim Departemen IT sebagai pedoman atau acuan untuk menyelesaikan problem dengan lebih cepat. Dan dengan adanya sistem tersebut, Departemen IT bisa melakukan pembenahan dan pengembangan guna meningkatkan kepuasan karyawan terhadap pelayanan Departemen IT. Dengan demikian untuk mewujudkan tujuan diatas penelitian ini berencana merancang sistem aplikasi berbasis $W e b$ dan menggunakan bahasa pemrograman PHP dengan frameworkCodeIgniter dan menggunakan basis data MariaDB.
\end{abstract}

Kata kunci: Helpdesk, Support, Web, PHP

\begin{abstract}
PT. Aplus Pacific, which has been established for almost 20 years, increasingly shows rapid development. Among the increase in employees and also the complexity of the company's manufacturing operational support systems, namely Enterprise Resource Planning (ERP) used by these employees. Based on these facts, this study looks at potential problems that will arise, namely the decline in support services from the IT Department for requests or complaints from employees relating to information technology needs both in terms of hardware and software. Because right now the team from the IT Department is still serving company employees with the PABX telephone line media. This has several drawbacks that can hamper the problem solving process, such as the incomparability of the existing telephone line with the number of complaints at the same time, until the process of solving the problem is relatively long even
\end{abstract}


though it is likely that the IT Department team has experienced or received the same complaint, due to the absence a well-stored knowledge base. Based on the results of the analysis carried out directly, the system of handling requests and complaints that are running requires changes. Therefore the main purpose of this research is to design a Helpdesk system that can accommodate the many needs and complaints of employees at PT. Aplus Pacific is quickly and also stored in a log so that it can be revisited at any time by the IT Department team as a guide or reference for solving problems more quickly. And with this system, the IT Department can make improvements and developments in order to increase employee satisfaction with the services of the IT Department. Thus to realize the above objectives this research plans to design a Web-based application system and use the PHP programming language with the CodeIgniter framework and use the MariaDB database.

Keywords: Helpdesk, Support, Web, PHP

\section{PENDAHULUAN}

Perkembangan yang pesat di bidang teknologi komputer, elektronik, telekomunikasi maupun mekanik telah menghasilkan berbagai aplikasi canggih dan cerdas yang merubah kehidupan manusia pada saat ini dan mendatang. Seiring dengan perkembangan zaman, peranan teknologi informasi dan komunikasi sangat berdampak positif dalam meningkatkan kualitas hidup manusia.

Pada objek penelitian yang penulis lakukan, hampir keseluruhan kegiatan operasional perusahaan sudah berbasis komputer. Maka dari itu, kegiatan operasional tersebut tidak luput dari kendala-kendala yang berhubungan dengan komputer baik hardware maupun softwarenya dan juga perangkat pendukungnya. Saat ini permasalahan yang dilaporkan oleh user (karyawan) kepada tim di Departemen IT masih diselesaikan secara manual dengan menelepon ke ruangan IT melalui jaringan internal telepon PABX, yaitu tanpa suatu sistem aplikasi yang dapat membantu untuk mempercepat penyelesaian permasalahan.

Hal tersebut memiliki beberapa kekurangan yang dapat menghambat proses penyelesaian masalah, seperti tidak sebandingnya line telepon yang ada dengan banyaknya keluhan di waktu yang bersamaan, sampai proses penyelesaian masalah yang relatif lama walaupun kemungkinan tim Departemen IT pernah mengalami atau menerima keluhan yang sama, dikarenakan tidak adanya basis pengetahuan yang tersimpan dengan baik.

Untuk dapat menyelesaikan permasalahan di atas, perlu dibuat suatu model aplikasi helpdeskonline untuk mendukung bagian IT dalam meningkatkan pelayanan karyawan. Hal ini dapat diselesaikan menggunakan berbagai metode penelitian diantaranya observasi, wawancara, studi pustaka. Dan untuk menggambarkan suatu sistem penulis menggunakan desain uml yang akan menggambarkan use casediagram, activitydiagram, sequencediagram dan classdiagram [1][2]. Sebagai gambaran dari hasil analisis menggunakan PIECES [3][4]. Untuk memberikan model gambaran sistem penulis juga menggunakan web sebagai media implementasi.

Sehingga diperlukan sistem aplikasi yang dapat menampung dan mewadahi setiap pertanyaan-pertanyaan dan keluhan-keluhan yang diajukan oleh user dari berbagai departemen. Dan juga dapat digunakan sebagai log (pedoman) agar kedepannya tim IT bisa menyelesaikan permasalahan yang sama dengan lebih cepat.

Banyak hal yang diusahakan oleh pihak manajemen suatu perusahaan untuk meningkatkan efisiensi. Mulai dari waktu kerja sampai dengan suku cadang mesin dikontrol untuk tujuan efisiensi [5][6]. Selain mengontrol kerja mesin, sistem monitoring juga bisa dimanfaatkan. HelpdeskSystem sebagai sebuah proses untuk mengumpulkan data dari berbagai sumber yang ada dan helpdesk dituntut untuk aktif memonitor dan merawat kebutuhan pengguna [7][8]. Adapun helpdesk bertujuan untuk memudahkan semua penggunaan perangkat IT dalam ruang lingkup perusahaan maupun lembaga instansi pemerintah yang melaporkan setiap permasalahan yang dihadapi [9][10]. Setiap permasalahan yang telah selesai ditindaklanjuti akan secara otomatis terdokumentasi dan dapat dijadikan referensi serta dapat 
menyajikan laporan untuk memenuhi kebutuhan informasi dalam suatu perusahaan maupun lembaga instansi pemerintah yang dapat diakses dengan cepat dan mudah. Sehingga, dapat menghasilkan solusi yang tepat dalam mengatur sumber daya yang ada.

\section{METODE PENELITIAN}

Metode penelitian merupakan suatu tata cara atau kegiatan pelaksanaan penelitian rangka untuk mengumpulkan informasi atau data serta melakukan investigasi terhadap data yang telah didapatkan tersebut. yang didasari oleh asumsi-asumsi dasar, pandangan-pandangan filosofis dan ideologis, pertanyaan dan isu-isu yang dihadapi [11][12]. Suatu penelitian mempunyai rancangan penelitian tertentu. Rancangan ini menggambarkan prosedur atau langkah-langkah yang harus ditempuh, waktu penelitian, sumber data dan kondisi arti untuk apa data dikumpulkan dan dengan cara bagaimana data tersebut dihimpun dan diolah untuk dianalisa dalam pembuatan laporan [13].

\subsection{Metode Observasi (Observation Research)}

Pada tahapan ini penulis melakukan pengamatan langsung dari objek penelitian terutama pada bagian IT, untuk mendapatkan data dan informasi yang akurat dan lengkap dari berbagai pihak yang terkait dan berhubungan dengan tema penelitian yang berhasil penulis rumuskan.

\section{a. Metode Wawancara (Interview Research)}

Penulis melakukan wawancara pada bagian IT yang mengolah data keluhan karyawan, penulis mendapatkan informasi berkaitan dengan penelitian penulis.

\section{b. Metode Studi Pustaka (Studi Literatur)}

Selain melakukan observasi penulis juga melakukan data dengan cara studi pustaka dalam metode ini penulis berusaha untuk melengkapi data-data yang diperoleh dengan membaca dan mempelajari dari buku-buku dan data-data yang relevan. Buku dan data tersebut digunakan penulis untuk membantu penganalisaan dan perancangan yang dilakukan.

\subsection{Metode Analisis Data}

Pada penelitian ini, metode analisis dilakukan dengan langkah-langkah melakukan pengamatan dan analisa terhadap sistem yang berjalan saat ini, serta menentukan UML (Unified Modeling Language) yang meliputi use case diagram, activity diagram, sequence diagram.

\section{PEMBAHASAN}

Untuk dapat menggambarkan prosedur secara keseluruhan diperlukan beberapa tahapan analisa sebagai bentuk pengumpulan informasi guna mendapatkan model yang sesuai dengan kebutuhan dan mampu memberikan solusi dengan cepat secara efektif dan efisien, mulai dari tahapan pengumpulan informasi dan kebutuhan, analisis dokumen, rancangan hubungan antar dokumen sampai dengan merancang model diagram database dan model perancangan sistem. Beberapa tahapan yang dimaksud sampai dengan model rancangan yang diciptakan dapat dilihat pada gambar $1,2,3,4,5$.

\subsection{Use Case Diagram Prosedur Berjalan}




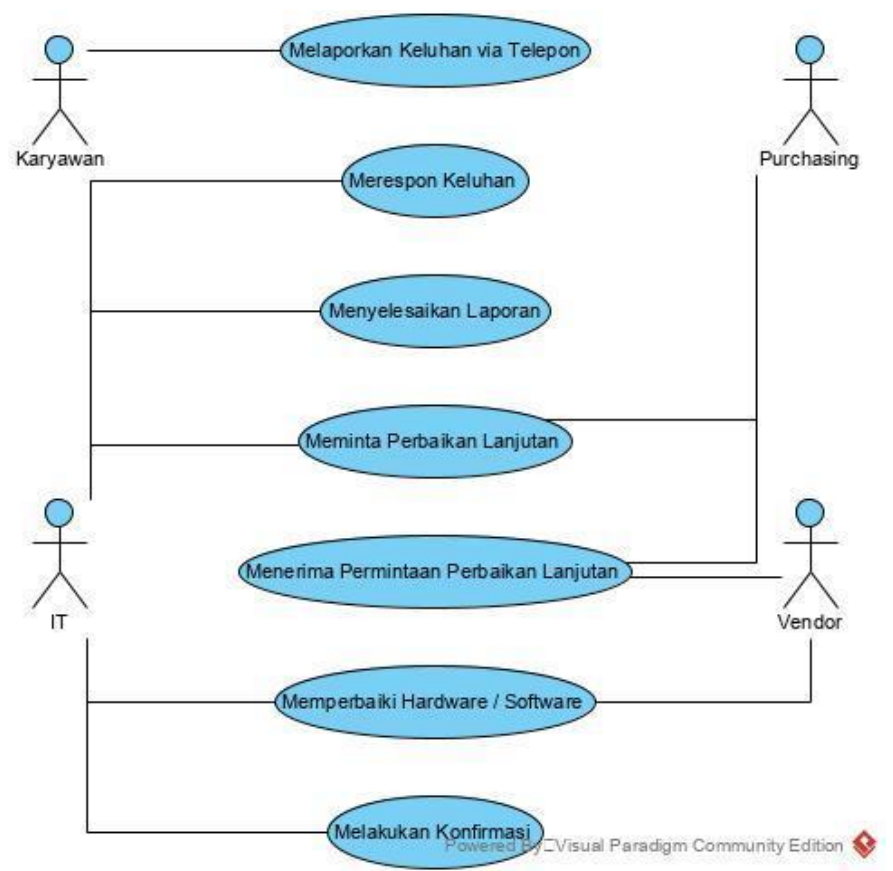

Gambar 1. Use Case Diagram Berjalan

Berdasarkan gambar use case Diagram (gambar 1) yang berjalan saat ini sistem yang mencakup seluruh kegiatan pada sistem penanganan laporan karyawan kepada bagian IT. Terdapat 4 (empat) Aktor yang melakukan kegiatan yaitu karyawan, purchasing, IT dan vendor yang berfungsi melaporkan keluhan, merespon keluhan, menyelesaikan laporan, meminta perbaikan lanjutan, menerima permintaan perbaikan lanjutan, memperbaiki hardware/software dan melakukan konfirmasi.

Terdapat juga 7 (tujuh) use case yang merupakan proses yang terjadi pada sistem berjalan yaitu melaporkan keluhan, merespon keluhan, menyelesaikan laporan, meminta perbaikan lanjutan, menerima permintaan perbaikan lanjutan, memperbaiki hardware/software dan melakukan konfirmasi yang melibatkan karyawan, purchasing, IT dan vendor.

\subsection{Activity Diagram Prosedur Berjalan}




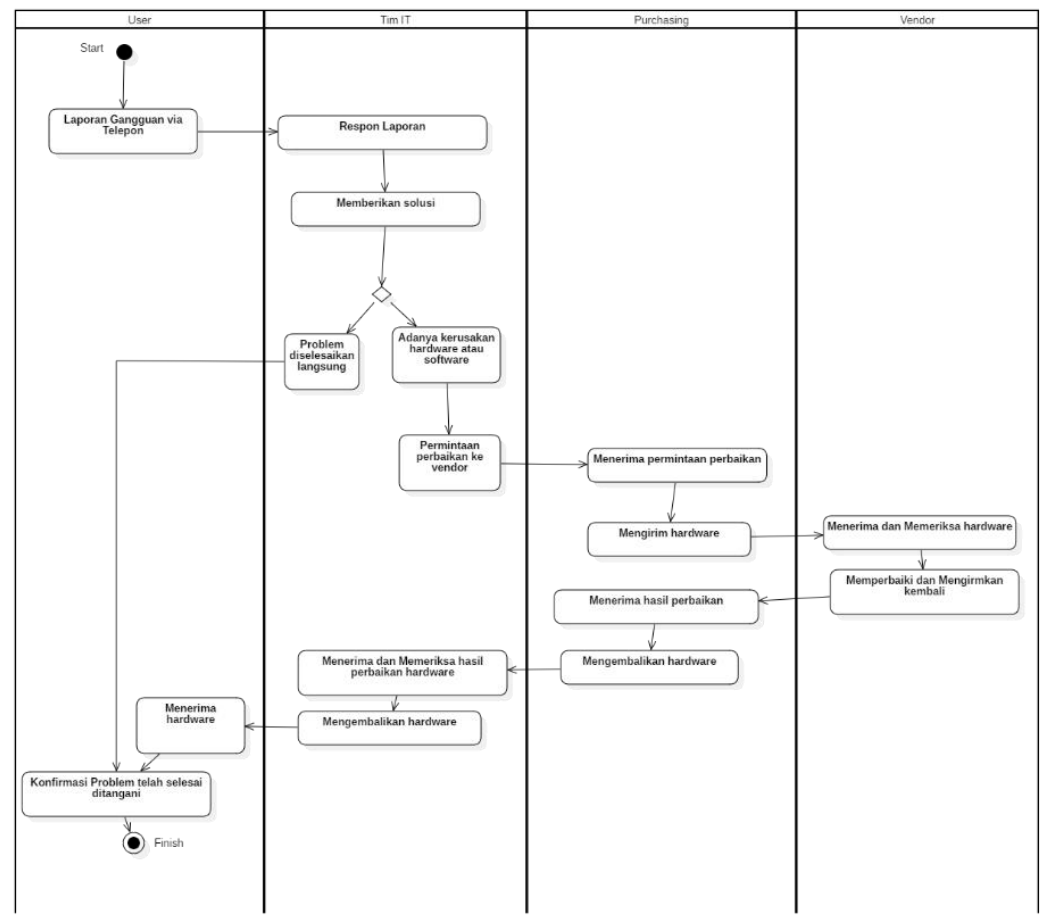

Gambar 2. Activity Diagram Berjalan

Berdasarkan gambar activity diagram (gambar 2) yang berjalan saat ini sistem mencakup seluruh kegiatan sistem penanganan laporan karyawan kepada bagian IT. Sistem ini melibatkan 4 (empat) Actor yaitu, user yang membuat laporan melalui telepon, kemudian bagian IT merespon laporan dari user lalu memberikan solusi dari laporan. Jika permasalahan dapat langsung diselesaikan maka bagian IT langsung konfirmasi kepada karyawan, tetapi jika memerlukan perbaikan lebih lanjut akan dikirim ke vendor melalui bagian purchasing. Setelah selesai diperbaiki, bagian IT akan melakukan tes hasil perbaikan. Kemudian akan dikembalikan ke karyawan. Lalu laporan dikonfirmasikan telah selesai.

\subsection{Sequence Diagram Prosedur Berjalan}

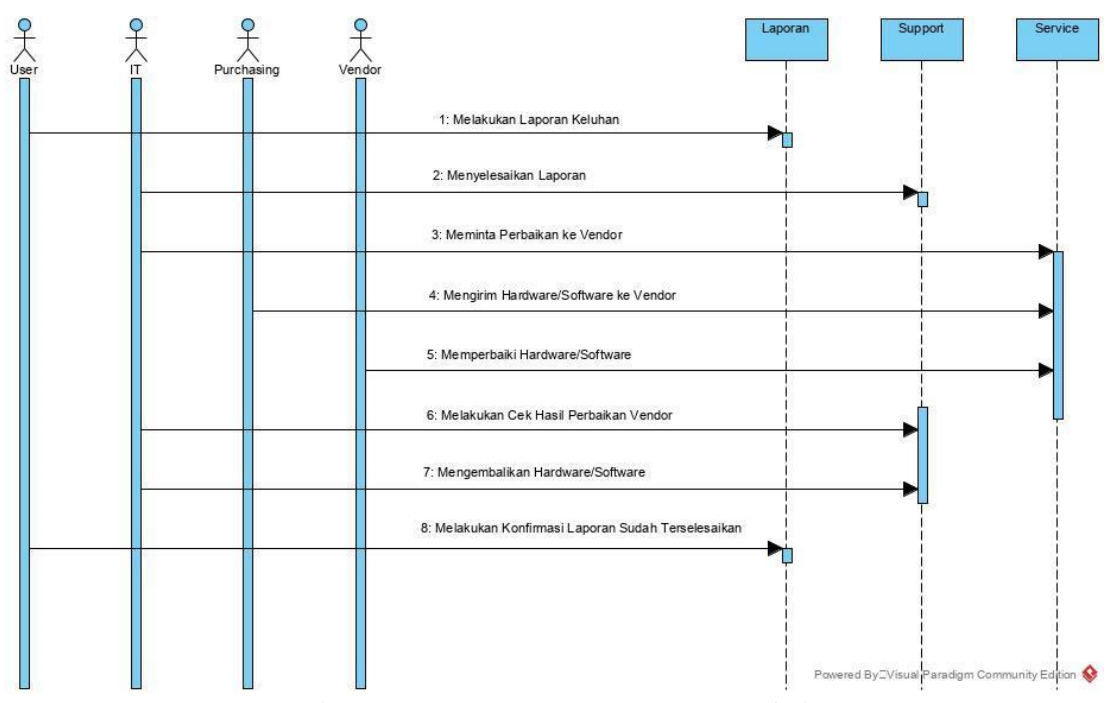

Gambar 3. Sequence Diagram Berjalan 
Berdasarkan gambar sequence diagram (gambar 3) yang berjalan saat ini terlihat 4 (empat) aktor yang melakukan kegiatan diantaranya: user, IT, purchasing dan vendor, yang akan menyelesaikan 8 message yaitu, melakukan laporan keluhan, menyelesaikan laporan, meminta perbaikan lanjutan, mengirim hardware/software ke vendor, memperbaiki hardware/software, melakukan cek hasil perbaikan vendor, mengembalikan hardware/software dan melakukan konfirmasi laporan sudah terselesaikan.

Rancangan diatas (gambar 1,2,3) merupakan gambaran prosedur yang berjalan dimana pada tahapan ini melibatkan beberapa proses seperti membuat laporan keluhan, menyelesaikan laporan, melakukan permintaan perbaikan lanjutan dan menerima permintaan perbaikan lanjutan. Dimana membuat laporan keluhan dibuat oleh user yang berfungsi untuk memberitahukan kendala yang dialami pada saat menggunakan asset IT. Menyelesaikan laporan yang dilakukan oleh ITyang berfungsi untuk menindaklanjuti hasil laporan user dan melakukan serangkain kegiatan dalam rangka memberikan solusi terhadap situasi yang dialami oleh user. Melakukan permintaan perbaikan lanjutan dilakukan oleh purchasingyang berfungsi untuk mengirimkan hardware/software yang belum bisa diperbaiki oleh IT ke vendor perangkat tersebut. Menerima permintaan perbaikan lanjutan dilakukan oleh vendor yang berfungsi untuk memperbaiki hardware/software dari purchasing.

\subsection{Class Diagram}

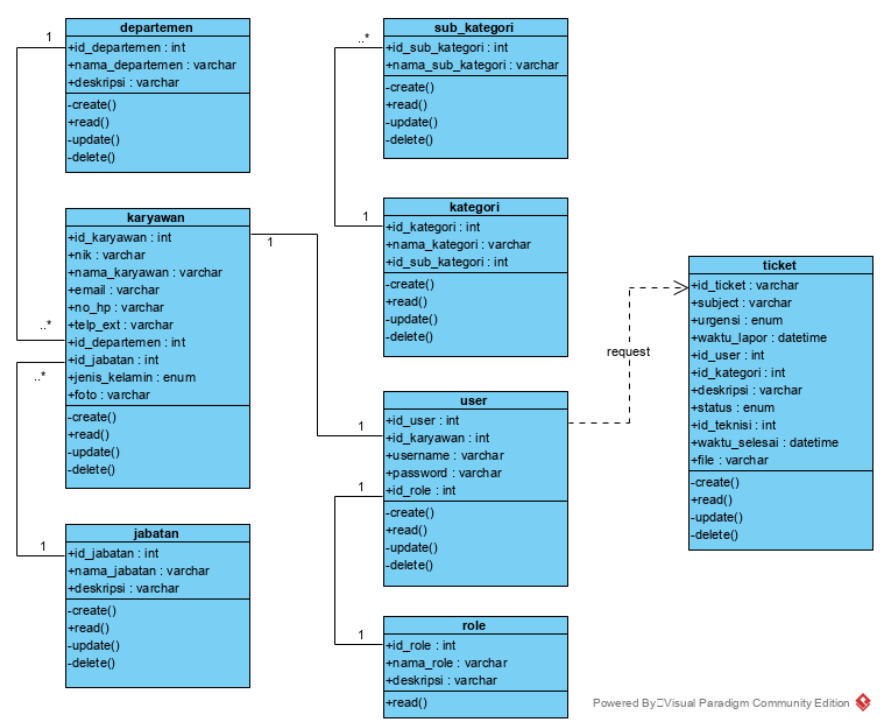

Gambar 4. Class Diagram

Berdasarkan gambar class diagram (gambar 4). Terdapat 8 (delapan) class yaitu, departemen, karyawan, jabatan, kategori, sub kategori, user dan role yang merupakan tabel master, serta ticket sebagai tabel transaksi.

Berdasarkan gambar class diagram (gambar 4) diatas dapat dilihat dengan jelas bahwa tingkat hubungan departemen dan karyawan yaitu one to many (1:M), tingkat hubungan jabatan dan karyawan one to many (1:M), tingkat hubungan user dan karyawan yaitu one to one (1:1), tingkat hubungan user dan role yaitu one to one (1:1), tingkat hubungan kategori dan sub kategori yaitu one to many (1:M), tabel ticket tercipta karena adanya request dari tabel user.

\subsection{Use Case Diagram Usulan}




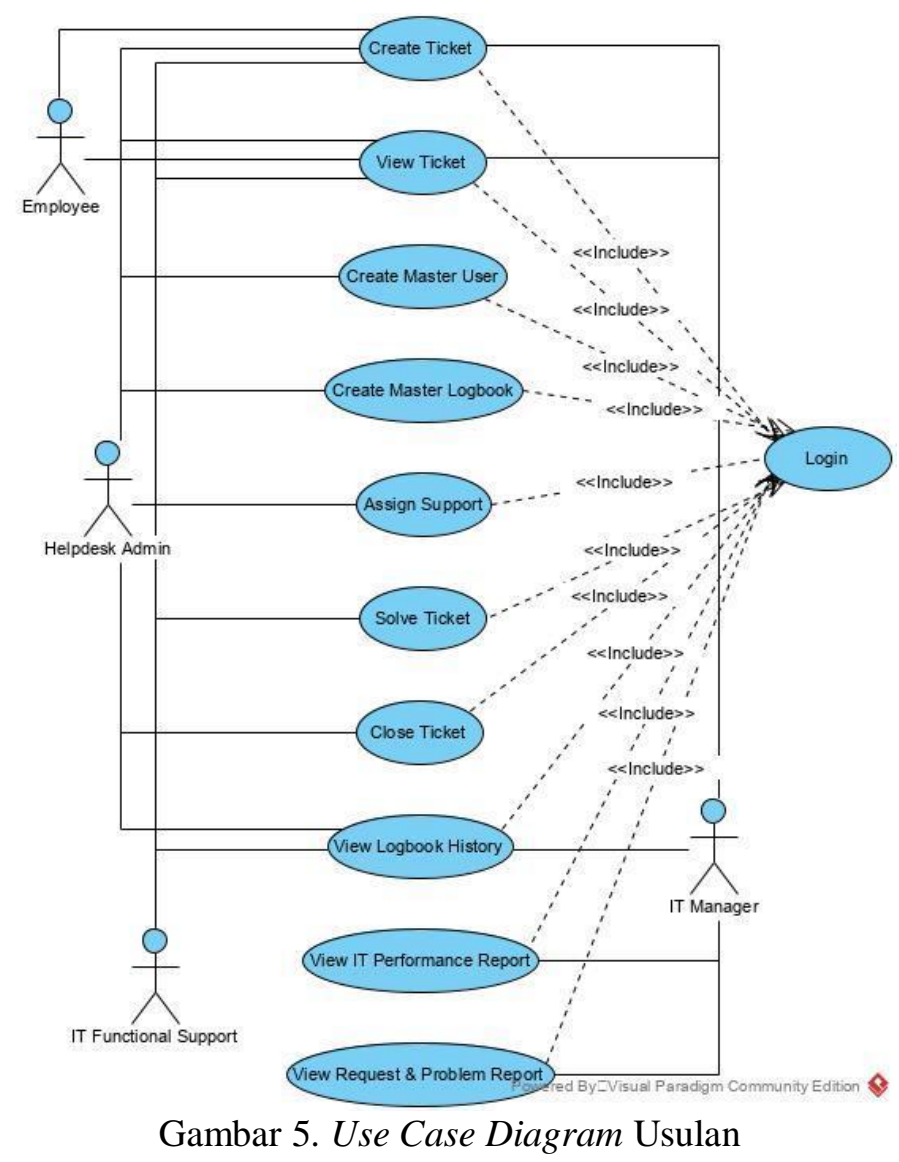

Berdasarkan gambar use case diagram usulan(gambar 5) terlihat jelas bahwa terdapat 11 (sebelas) use case yang terdiri dari login yang di dalamnya ada use case create ticket dan view ticket yang terhubung dengan actoremployee, helpdeskadmin, IT functionalsupport dan IT Manager. Lalu ada usecasecreatemasteruser, createmasterlogbook, assignsupport dan closeticket yang terhubung dengan helpdeskadmin. Ada juga usecasesolveticket yang terhubung dengan actor IT functionalsupport. Kemudian usecaseviewlog bookhistory yang terhubung dengan aktorhelpdeskadmin, IT functionalsupport dan IT Manager. Dan terakhir usecaseview IT performancereport dan viewrequest\&problemreport yang terhubung dengan actor IT Manager.

Usecasediagram sebagai bentuk rancangan sistem yang akan diciptakan (gambar 8, 9 dan 10) merupakan desain model tampilan utama yang berorientasi pada kebutuhan menu pada aplikasi yang disiapkan, selain itu untuk kebutuhan penyimpanan informasi data agar dapat digunakan secara histori juga digambarkan dalam bentuk classdiagram (gambar 4) lengkap dengan informasi field dan tipe data sesuai kebutuhan penyimpanan data.

\section{IMPLEMENTASI}

\subsection{Rancangan Basis Data}

Untuk dapat menggambarkan bentuk basis data secara utuh, peneliti menggunakan aplikasi phpmyadmin sebagai bentuk gambaran dasar, dan pada akhirnya bentuk rancangan basis data ini dapat disesuaikan menggunakan apa saja sesuai kebutuhan.
a. Tabel Master: Karyawan
Primary Key : nik
Foreign Key 
Structure Tabel : \{ nik, nama_karyawan, email, no.hp, telp_ext, id_departemen, id_jabatan, jenis_kelamin, foto \}

\begin{tabular}{|c|c|c|c|c|c|c|c|c|}
\hline & \# & Name & Type & Collation & Attributes & Null & Default Comments Extra & Action \\
\hline$\square$ & 1 & nik & $\operatorname{int}(11)$ & & & No & None & $\theta$ Change $\odot$ Drop $\nabla$ More \\
\hline$\square$ & 2 & nama_karyawan & $\operatorname{varchar}(100)$ & utf8mb4_general_ci & & No & None & $\theta$ Change $\odot$ Drop $\nabla$ More \\
\hline$\square$ & 3 & email & $\operatorname{varchar}(50)$ & utf8mb4_general_ci & & No & None & Change $\odot$ Drop $\nabla$ More \\
\hline$\square$ & 4 & no_hp & bigint(20) & & & No & None & $\theta$ Change $\odot$ Drop $\nabla$ More \\
\hline$\square$ & 5 & telp_ext & bigint(20) & & & No & None & Change $\odot$ Drop $\nabla$ More \\
\hline$\square$ & 6 & id_departemen & $\operatorname{int}(11)$ & & & No & None & $\theta$ Change $\odot$ Drop $\nabla$ More \\
\hline$\square$ & 7 & id_jabatan & $\operatorname{int}(11)$ & & & No & None & $\theta$ Change $\odot$ Drop $\nabla$ More \\
\hline$\square$ & 8 & jenis_kelamin & enum('PRIA', WANITA', ", ") & utf8mb4_general_ci & & No & None & Change $\odot$ Drop $\nabla$ More \\
\hline$\square$ & 9 & foto & $\operatorname{varchar}(100)$ & utf8mb4_general_ci & & No & None & Change $\odot$ Drop $\nabla$ More \\
\hline
\end{tabular}

Tabel 1. Tabel Karyawan

b. Tabel Master: Departemen

Primary Key : id_departemen

Foreign Key : -

Structure Tabel : \{id_departemen, nama_departemen, deskripsi \}

\begin{tabular}{|c|c|c|c|c|c|c|c|c|}
\hline & $\#$ & Name & Type & Collation & Attributes & Null & Default Comments Extra & Action \\
\hline$\square$ & 1 & id_departemen & int(11) & & & No & None & $\checkmark$ Change $\odot$ Drop $\nabla$ More \\
\hline$\square$ & 2 & nama_departemen & $\operatorname{varchar}(50)$ & utf8mb4_general_ci & & No & None & $\diamond$ Change $\odot$ Drop $\nabla$ More \\
\hline$\square$ & 3 & deskripsi & text & utf8mb4_general_ci & & No & None & Change $\odot$ Drop $\nabla$ More \\
\hline
\end{tabular}

Tabel 2. Tabel Departemen

c. Tabel Master: Jabatan

Primary Key : id_jabatan

Foreign Key : : -

Structure Tabel $\quad: \quad\{$ id_jabatan, nama_jabatan, deskripsi $\}$

\# Name Type Collation Attributes Null Default Comments Extra Action

$\begin{array}{lllll}\square & \text { id_jabatan } P \text { int(11) } & \text { No None } & \text { Change } \odot \text { Drop } \nabla \text { More } \\ \square 2 & \text { nama_jabatan varchar(100) utf8mb4_general_ci } & \text { No None } & \text { Change } \odot \text { Drop } \nabla \text { More } \\ \square 3 & \text { deskripsi } \quad \text { text } \quad \text { utfomb4_general_ci } & \text { No } & \text { None }\end{array}$

Tabel 3. Tabel Jabatan

d. Tabel Master: User

Primary Key $\quad$ : id_user

Foreign Key : : -

Structure Tabel : $\{$ id_user, nik, username, password, id_role \}

\begin{tabular}{|c|c|c|c|c|c|c|c|c|}
\hline & $\#$ & Name & Type & Collation & Attributes & Null & Default Comments Extra & Action \\
\hline$\square$ & 1 & id_user & $\operatorname{int}(11)$ & & & No & None & $\checkmark$ Change $($ Drop $\nabla$ More \\
\hline$\square$ & 2 & nik & $\operatorname{int}(11)$ & & & No & None & $\checkmark$ Change $\odot$ Drop $\nabla$ More \\
\hline$\square$ & 3 & username & $\operatorname{varchar}(50)$ & utf8mb4_general_ci & & No & None & $\checkmark$ Change $\odot$ Drop $\nabla$ More \\
\hline$\square$ & 4 & password & $\operatorname{varchar}(50)$ & utf8mb4_general_ci & & No & None & Change $(-)$ Drop $\nabla$ More \\
\hline$\square$ & 5 & id_role & $\operatorname{int}(11)$ & & & No & None & $\checkmark$ Change $(-)$ Drop $\nabla$ More \\
\hline
\end{tabular}

Tabel 4. Tabel User

e. Tabel Master: Role

Primary Key : id_role 
Foreign Key : : -

Structure Tabel : \{id_role, nama_role, deskripsi \}

\begin{tabular}{|c|c|c|c|c|c|c|c|c|}
\hline & $\#$ & Name & Type & Collation & Attributes & Null & Default Comments Extra & Action \\
\hline$\square$ & 1 & id_role & $\operatorname{int}(11)$ & & & No & None & Change $\odot$ Drop $\nabla$ More \\
\hline$\square$ & 2 & nama_role & $\operatorname{varchar}(50)$ & utfomb4_general_ci & & No & None & $\theta$ Change $\odot$ Drop $\nabla$ More \\
\hline$\square$ & 3 & deskripsi & text & utfomb4_general_ci & & No & None & Change $\odot$ Drop $\nabla$ More \\
\hline
\end{tabular}

Tabel 5. Tabel Role

f. Tabel Master: Kategori

Primary Key : id_kategori

Foreign Key : : -

Structure Tabel : $\{$ id_kategori, nama_kategori, id_sub_kategori $\}$

\begin{tabular}{|c|c|c|c|c|c|c|c|}
\hline$\#$ & Name & Type & Collation & Attributes & Null & Default Comments Extra & Action \\
\hline 1 & id_kategori & $\operatorname{int}(11)$ & & & No & None & $\nabla$ Change $\odot$ Drop $\nabla$ More \\
\hline 2 & nama_kategori & $\operatorname{varchar}(50)$ & utfomb4_general_ci & & No & None & $\theta$ Change $\odot$ Drop $\nabla$ More \\
\hline 3 & id_sub_kategori & $\operatorname{int}(11)$ & & & No & None & $\nabla$ Change $\odot$ Drop $\nabla$ More \\
\hline
\end{tabular}

Tabel 6. Tabel Kategori

g. Tabel Master: Sub_Kategori

Primary Key : id_sub_kategori

Foreign Key : : -

Structure Tabel : \{id_sub_kategori, nama_sub_kategori \}

\# Name Type Collation Attributes Null Default Comments Extra Action

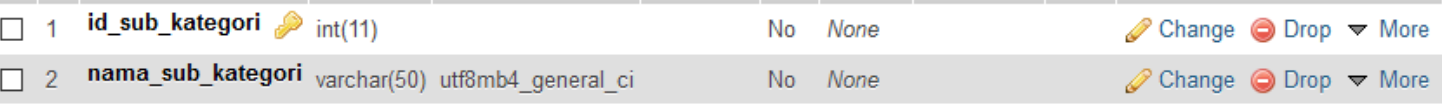

Tabel 7. Tabel Sub_Kategori

h. Tabel Transaksi: Ticket

Primary Key : id_ticket

Foreign Key : :

Structure Tabel : \{ id_ticket, subject, urgensi, waktu_lapor, id_user, id_kategori, deskripsi, status, id_teknisi, waktu_selesai, file \}

\begin{tabular}{|c|c|c|c|c|c|c|c|c|c|}
\hline & $\#$ & Name & Type & Collation & Attributes & Null & Default Comments Extra & Action & \\
\hline$\square$ & 1 & id_ticket & $\operatorname{int}(11)$ & & & No & None & 2 Change Drop & $\nabla$ More \\
\hline$\square$ & 2 & subject & $\operatorname{varchar}(50)$ & utf8mb4_general_ci & & No & None & Change $(9)$ Drop & $\nabla$ More \\
\hline$\square$ & 3 & urgensi & enum('HIGH', 'MEDIUM', 'LOW, ") & utf8mb4_general_ci & & No & None & Change Drop & $\nabla$ More \\
\hline$\square$ & 4 & waktu_lapor & datetime & & & No & None & Change $(-)$ Drop & $\nabla$ More \\
\hline$\square$ & 5 & id_user & $\operatorname{int}(11)$ & & & No & None & Change Drop & $\nabla$ More \\
\hline$\square$ & 6 & id_kategori & $\operatorname{int}(11)$ & & & No & None & Change $\odot$ Drop & $\nabla$ More \\
\hline$\square$ & 7 & deskripsi & text & utf8mb4_general_ci & & No & None & 2 Change Drop & $\nabla$ More \\
\hline$\square$ & 8 & status & enum(OPEN', 'RESPOND', 'SOLVED', 'CLOSE') & utf8mb4_general_ci & & No & None & Change $\odot$ Drop & $\nabla$ More \\
\hline$\square$ & 9 & id_teknisi & $\operatorname{int}(11)$ & & & No & None & 2 Change Drop & $\nabla$ More \\
\hline$\square$ & 10 & waktu_selesai & datetime & & & No & None & 2 Change $\odot$ Drop & $\nabla$ More \\
\hline$\square$ & 11 & file & $\operatorname{varchar}(100)$ & utf8mb4_general_ci & & No & None & Change Drop & $\nabla$ More \\
\hline
\end{tabular}

Tabel 8. Tabel Ticket

\subsection{Grafik Kondisi Asset IT}


ISSN: 2461-1409

Online ISSN: $2655-5298$

\section{GRAFIK MONITORING STATUS KONDISI ASSET IT \\ BULAN MARET 2020}

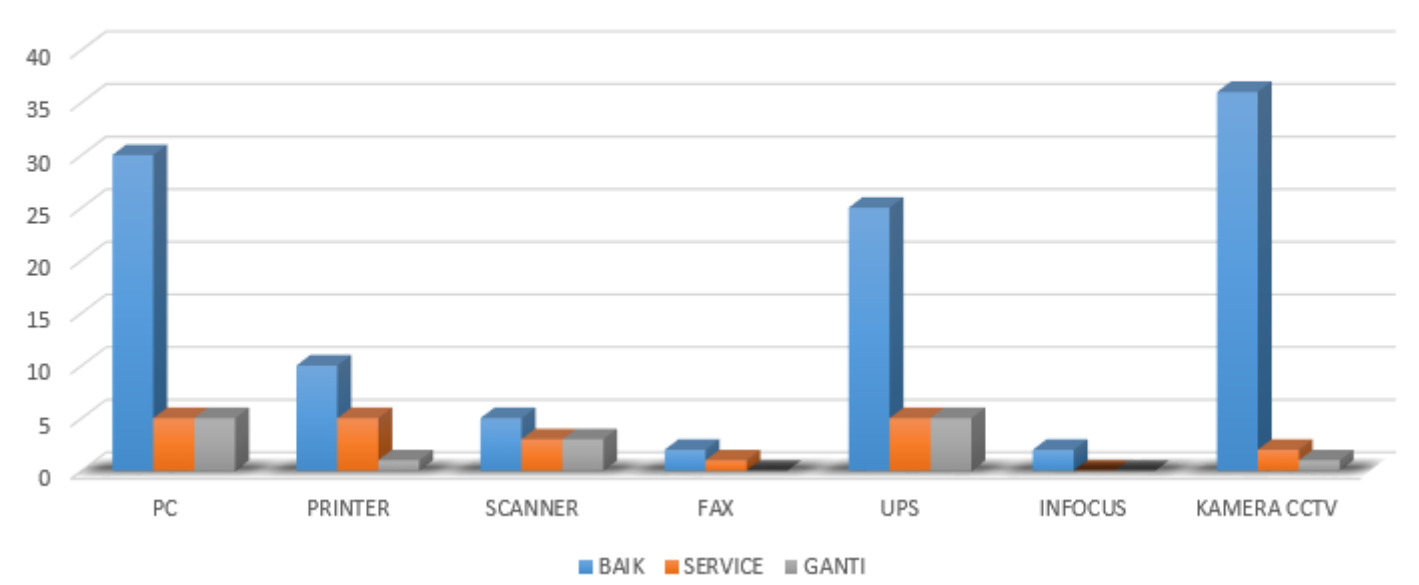

Gambar 6. Grafik Kondisi Asset IT Bulan Maret 2020

Grafik di atas (gambar 6) merupakan grafik kondisi asset IT selama bulan Maret 2020. Grafik di atas bisa diambil berdasarkan Data Warehouse, sebagaimana didefinisikan "Doing Data Warehouse $(D W)$ to your business or system is not only think about the trend only, but how to understand the DW knowledge itself and how to implement it" [5]. Dan bagaimana cara mengukurnya "Measures are a standard unit used to express the size, amount, or degree of something, qualities are often difficult to be measured as it needs to have some certain parameter or elements, and those parameters must be quantifiable and verifiable" [10].

\subsection{Diagram HIPO}

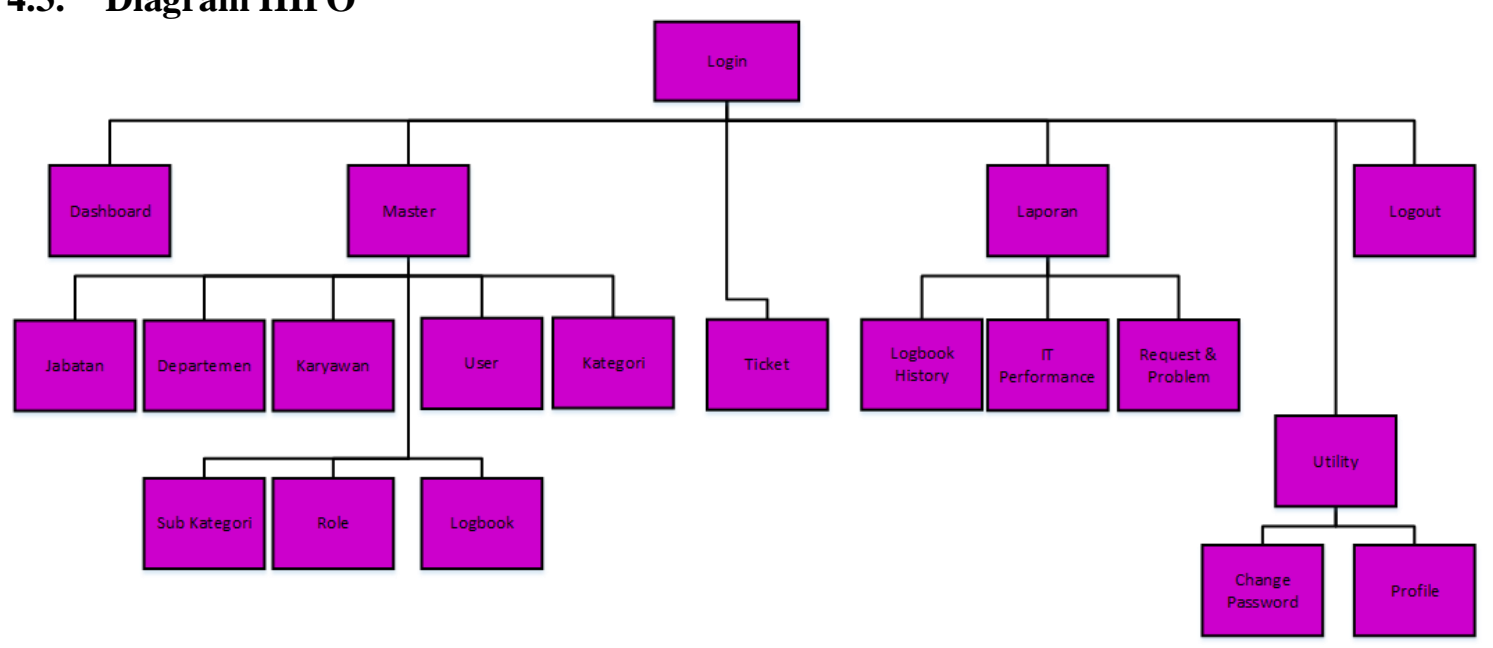

Gambar 7. HIPO

Untuk menggambarkan struktur menu dari sistem yang dirancang dapat digambarkan dengan diagram HIPO (Hierarchy Input Process Output).Untuk menyediakan suatu struktur guna memahami fungsi-fungsi dari program. Terlihat dari diagram HIPO diatas (gambar 7) terdapat 1 (satu) fungsi utama (diagram 0) dan 3 (tiga) fungsi dibawahnya, yaitu fungsi menu master (diagram 1), menu ticket (diagram 2) dan menu laporan (diagram 3). Didalam fungsi menu master (diagram 1) terdapat 8 (delapan) fungsi sub menu yaitu fungsi menu pengelolaan data jabatan (diagram 1.1), pengelolaan data departemen (diagram 1.2), pengelolaan data karyawan (diagram 1.3), pengelolaan data user (diagram 1.4), pengelolaan data kategori (diagram 1.5), pengelolaan data sub kategori (diagram 1.6), pengelolaan data role (diagram 1.7), 
pengelolaan data logbook (diagram 1.8). Di Dalam fungsi laporan (diagram 3) terdapat 3 (tiga) fungsi sub menu yaitu fungsi menu pengelolaan data log bookhistory (diagram 3.1), pengelolaan IT performance (diagram 3.2) dan pengelolaan request\&problem (diagram 3.3).

\subsection{Rancangan Tampilan}

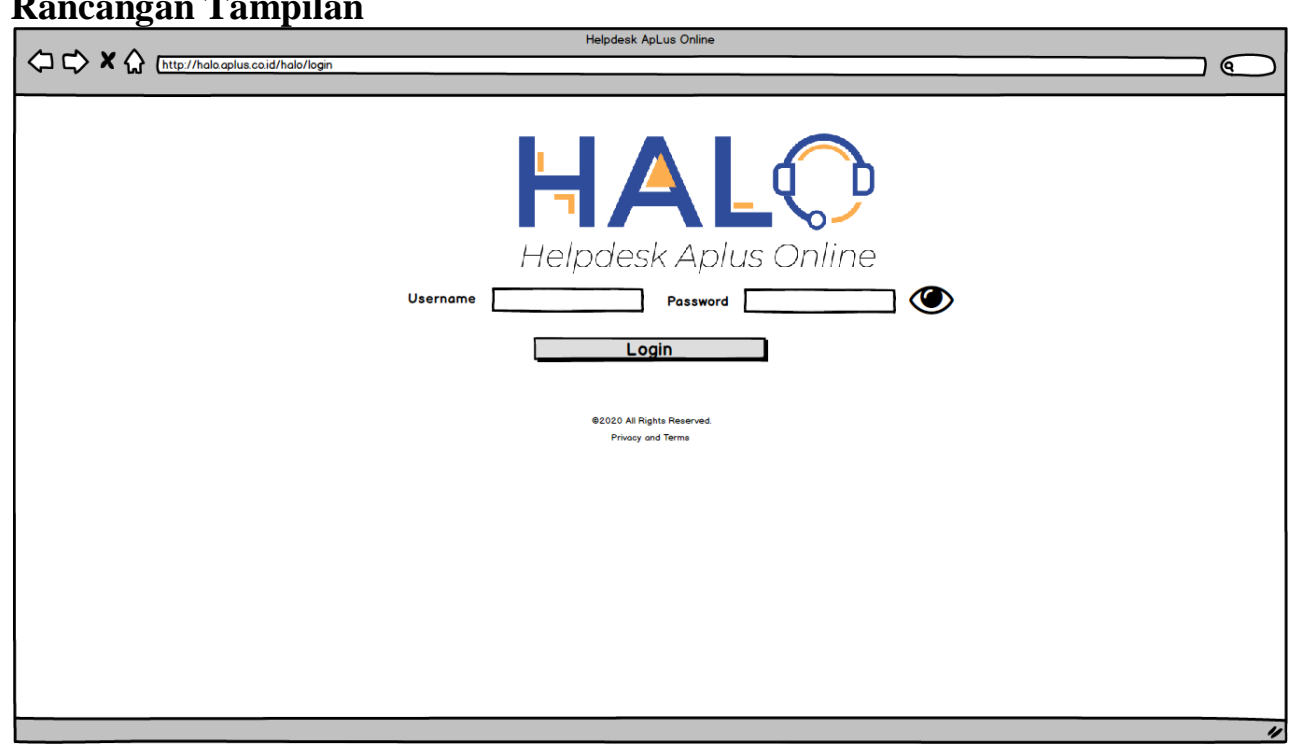

Gambar 8 Rancangan Layar Login

Terlihat pada tampilan layar diatas (gambar 8) merupakan tampilan layar login yang terdiri dari input username, password dan buttonlogin.

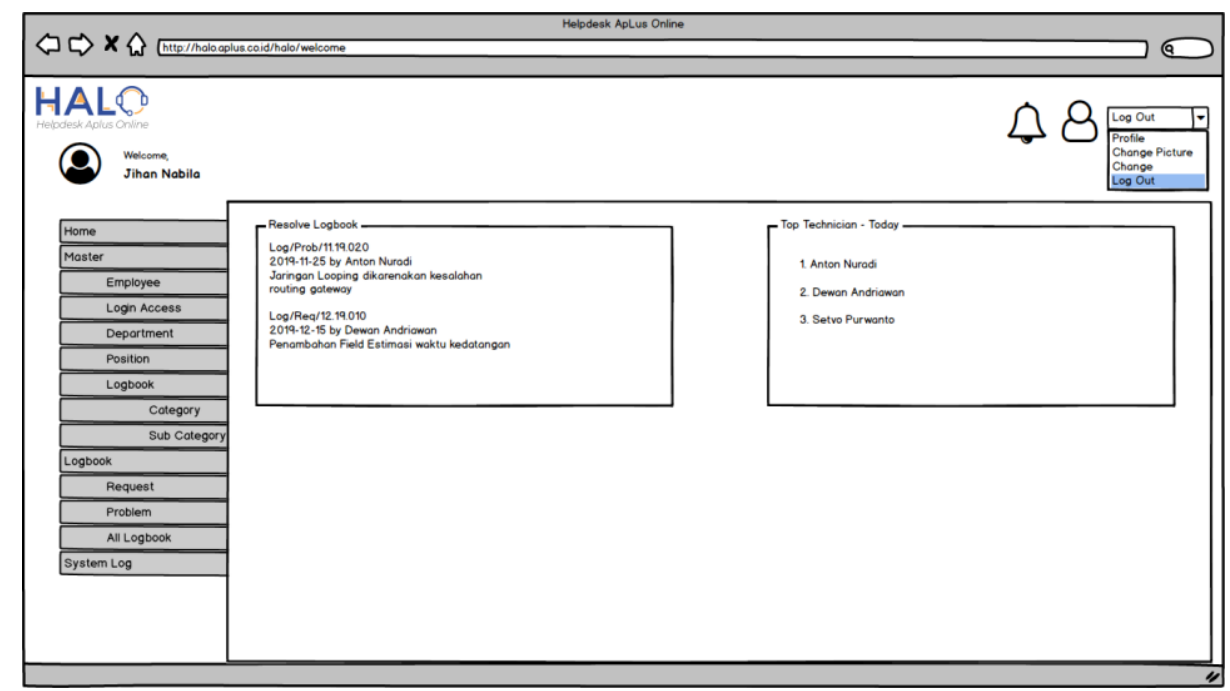

Gambar 9 Rancangan Layar Dashboard

Terlihat pada tampilan layar diatas (gambar 9) merupakan tampilan layar dashboard dengan level helpdeskadmin (fullrole) yang terdiri dari menu master, menu log book (ticket) dan menu laporan. 


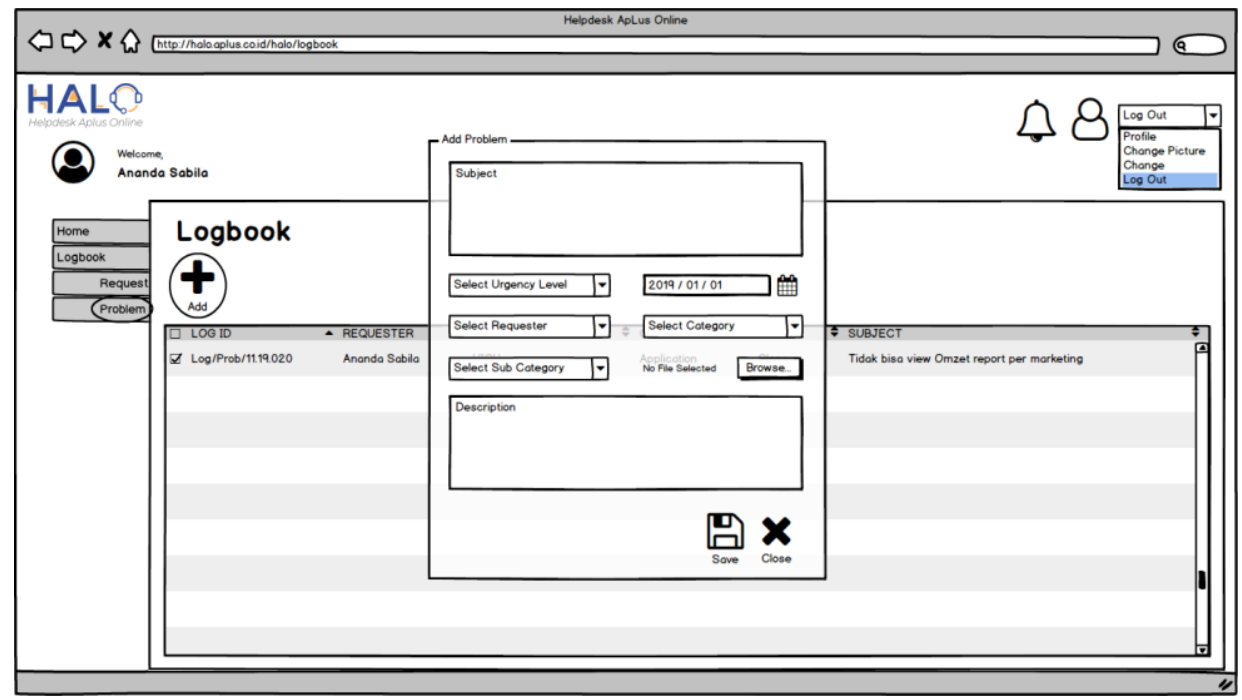

Gambar 10 Rancangan Layar Transaksi CreateTicket

Terlihat pada tampilan layar diatas (gambar 10) merupakan tampilan layar transaksi pembuatan tiket laporan yang terdiri dari menu request dan problem, tergantung dari kendala yang alami oleh karyawan yang bersangkutan.

\section{KESIMPULAN}

Berdasarkan hasil analisis dari rumusan masalah yang telah dilakukan, dapat disimpulkan bahwa sistem penanganan keluhan karyawan kepada bagian IT yang berjalan saat ini masih menggunakan teknik manual dimana dalam prosesnya memakan waktu yang lama sehingga berdampak pada lamanya pemberian solusi terhadap permasalahan yang dihadapi. Tingginya tingkat manualisasi dalam sistem penanganan keluhan ini akan berakibat pada menurunnya kualitas tingkat pelayanan kepada karyawan. Untuk mengatasi semua ini, diperlukan sistem yang dapat mengakomodir kebutuhan dokumentasi yang cepat dan akurat, sehingga tidak ada lagi keterlambatan atau kesalahan dalam penyelesaian kendala yang dialami karyawan. Hal ini dapat dicapai dengan menggunakan beberapa metode penyelesaian seperti menggunakan uml untuk menggambarkan rancangan sistem, $M y S q l$ untuk pengolahan basis data dan php sebagai bahasa pemrograman.

\section{DAFTAR PUSTAKA}

[1] Junaidi, Junaidi, Siti Euis Iyana Nurlia, and Fira Arbaimaniar Nurul. "Model Sistem Pengolahan Data Pengaduan Karyawan untuk Mengukur Kepuasan Pelayanan dalam Meningkatkan Kinerja Perusahaan." Journal Cerita 6.1: 63-73.

[2] Supriati, Ruli, Junaidi Junaidi, and John Hendri. "Implementation of Outsourcing Employee Sales System For Verification and Acceleration Salary Transparency." Creative Communication and Innovative Technology Journal 13.1: 76-87. [3] Cholisoh, Novi, Sendy Zul Friandi, and Grees Wiliam. "Faktor Pengaruh Lingkungan Kerja dan Disiplin Kerja terhadap Kontribusi Kinerja Karyawan pada PT. Gapura Angkasa Bandara Soekarno Hatta." Cyberpreneurship Innovative and Creative Exact and Social Science 5.1: 44-63.

[4] Junaidi, Junaidi, Al Husain, and Jumaria Manda. "Rancang Bangun Sistem Informasi Simpan Pinjam sebagai Monitoring Unit Kerja untuk Mengukur Kinerja Angsuran Pembayaran." Innovative Creative and Information Technology 5.2: 213-224. 
[5] M. Subekti, Warnars Junaidi, H.L.H.S., Y. Heryadi, "The 3 steps of best data warehouse model design with leaning implementation for sales transaction in franchise restaurant", Cybernetics and Computational Intelligence (CyberneticsCom) 2017 IEEE International Conference on, 20-22 Nov 2017.

[6] Cholisoh, Novi, Henderi Henderi, and Siti Khodijah. "Rancang Bangun Sistem Administrasi Perizinan Kursus untuk Meningkatkan Pelayanan Masyarakat pada Pusat Pemerintahan." Journal Cerita 5.2: 189-201.

[7] Junaidi, Junaidi, Sutrisno Sutrisno, and Koriatul Janah. "Model Aplikasi Purchasing System Untuk Monitoring Stok Dalam Mengurangi Tingkat Kerugian." Journal Sensi 5.1 (2019): 86-98.

[8] Thiehunan, Hendrik.,Thiang. (2002). Sistem Monitoring Keamanan Menggunakan PLC FESTO. Jurnal Teknik Elektro Vol.2 No.2.

[9] Sudarto, Ferry, Novi Cholisoh, and Cheetah Savana Putri. "Sistem Informasi Pengambilan Kartu Ujian Mahasiswa Plus (Kum+) Berbasis Web." E-JURNAL JUSITI: Jurnal Sistem Informasi dan Teknologi Informasi 7.2 (2018): 153-162.

[10] J. Junaidi, A. Julianto, N. Anwar, S. Safrizal, H.L.H.S. Warnars, K. Hashimoto, "Perfecting a Video Game with Game Metrics", Telkomnika, vol. 16, no. 3, pp. 13241331, June 2018

[11] Zainuddin, A., Junaidi, J., \& Putra, R. D. (2017). Design of E-Commerce Payment System at Tokopedia Online Shopping Site. Aptisi Transactions On Management, 1(2), 143-155.

[12] Nugroho, Hendra Setyo Adi., Sukmaaji, Anjik., Jatmika, Kurniawan. (2013). Sistem Informasi IT Help Desk Prioritas Kerja Berbasis Web pada PT Pelabuhan Indonesia III Cabang Tanjung Perak. Jurnal JSIKA 2

[13] Sunarya, Lusyani, Ageng Setiani Rafika, and Novi Cholisoh. "Pengaruh Ilearning Dan Profesionalisme Dosen Terhadap Kinerja Jurusan Teknik Informatika Stmik Raharja Tangerang." 